employed, great care being taken to make sure that the long sleeves of the jacket are bound firmly round the pitient's wrista, otherwise he will withdraw his hands and soon set himself free. When the jacket and sheet have been properly adjusted the patient is secure, but it is not desirable that he should be kept tied up a minute longer than is necessary. If he still refuses to swallow the drauchlit what is to be done? A hypodermic injection of morphia might be given, but I confess to a prejudice against this practice in fever cases from a fear of causing local irritation, boils, \&c., and, besides, the pain inflicted by the thrust of the needle, though slight, would confirm the patient in his belief thet he was in the hands of the enemy.

I fiad the following method to wor's w 11 :-Morphia suppositories are administered till the patient becomes quiet and drowsy. He is then manageable. The jacket and sheet can be removed, and warm dry flunels, Wc., put on. 'The probability is that he can now be got to take a draught, or at least to swallow passively. If he still refuses, morphia suppositories can be aumiaistered as required. As to the nature of the draught, I may state that I adhere to the hydrate of chloral, long ago tried and rec smmended by Dr. James B. Russell in the treatment of fever cases. When there is simply insomnia twenty or twenty-five grains of chloral hydrate in syrup (repeated, if necessary, in an hour) generally secures good sleep for an adult. When, bowever, there is violent delirium the addition of five or ten minims of solution of muriate of morphia causes the end in view to be more rapidly and effectually attained. But this combination of chloral and morphia is well known to be a formidable one ; it requires to be carefully administered, and the effects must be closely watched. When the narcotics require to be given for a loog time on account of persistent delirium, it is convenient to prescribe a mixture, each dose of which contains ten grains of chloral and five or ten minims of solution of muriate of morphia, the interval between the doses being determined by the effect produced. Respiratory embarra:sments, lividity of nails, \&r., are serious contra-indications to the use of narcotics. When suppositories and draughts have both been given in a case, this should be well borne in mind so as to estimate the combined effect. In the treatment of violent delirium in fever, narcotics wisely given may save life; improperly given they may hasten, or even directly cause, deatl. In prescribing them no routine practice can be adopted, and their administration demands the most careful personal supervision of the physician in attendance.

Belvidere.

TWO CASES OF

HAMATOCELE OF THE TUNICA VAGINALIS, THE ONE CHRONIC, THE OTHER ACUTE.

BY JAMES PATON, M. D.,

SLRGEON TO THE GREENOCK HOSPITAL.

CAse 1.-P. R—, a labourer, aged sixty yeara, was admitted to the medical ward of the Greenock Infirmary on Feb. 23rd, 1883, for some obscure pain in the hack. In the course of examination the house-surgeon detected a large scrotal swelling. $O n$ the 25 th $I$ was requested to see the case. The swelling was the size of a large cocoa-nut, pyriform in shape, and on tilting up with the hand felt very heavy. The skin was freely movable over the whole mass, with no external discolouration. There was no pain on manipulation, except at a small space at the lower and posterior part of the swelling. The cord could be distinctly felt at the external ring; no impulse on coughing. The feeling on palpation was more that of solidity than of deep fluctuation, so much so that $I$ at first was inclined to the diagnosis of sarcocele. There was no tı ansparency. I obtained a small Southey's exploring-needle, by which some very dark, porter-coloured fluid escaped, which contained abundance of cholesterine. 'The man's own account of the previous condition of his scrotum was indefiuite, and rather untrustworthy, but, so far as can be made out, it would seem there has becn a swelling for about forty years. He noticed his scrotum begin to swell when about twenty years of age. 'Two or three years afterwards he met with a railway accident, by which he was very severely injured, having one of his legs broken, and otherwise severely bruised. After this accident he states that the swelling was constantly present to some extent, but coming and going; and he distinctly attirms that when exposed to cold or walking about it became decidedly less, and incre tsed again as soon as he lay down and got warm in bed. About two years ago he rot intoxicated one evening, and in the morning when he awoke he found his scrotum sery much distended, discoloured, and painful; whether he had been hurt by a fall or blow he could not say. The swelling has never been subjected to any interference whatever. The diagnosis was that of chronic hæmatocele, for which extirpation was proposed to the man, and to which he willingly assented. Accordingly, on March 2nd, I removed the tumour by an elliptical incision, beginning at the external ring, including a large piese of the scrotal integuments, dissected down to the tunica vaginalis, from which the scrotal structures were easily separated. The cond was tied with chromicised catgut. The whole was done with the usual aseptic precautions. Unfortunately during the $\mathrm{ni}$ ht, being somewhat restless, he disarranged the dressings, leaving the lower part of the wound exposed. It was then dressed with a glycerine solution of carbolic acid, and afterwards with simple boracic dressings. There was little or no constitutional disturbance, and the wound healed up entirely. Un cutiog into the tumour after removal the cavity was found filled with the beforementioned flaid. The walls of the tunica vaginalis were very much thickened, in some places half an inch, presenting a laminated appearance, and feeling cartilaginous. At the lower and posterior part of the tumour was found the testicle, disorganised, and embedded in the thickened walls, this being the spot where he experienced pain when touched. The internal surface of the tunica was corrugated, or rather nodulated, with masses of fibrinous coagulum adhering to the wall. I should have stared that the sphygmographic tracing was distinctly seoile.

C.SE 2-Mr. McG-, aged sixty-six years, retired. Has had hydrocele for nine or ten years, which he attributes to an accident by falling on the bitts of a yacht while pulling in a rope which broke. Has been in the habit of getting it tapped once a year or so. $\mathrm{He}$ had no pain or uneasiness beyond the inconvenience of the size and weight of the swelling, On April 17th, 1883, some fowls belonging to a neighbuuring proprietor had come into his garden (which they were in the habit of doing), and he made a rush at them, caugbt one, and was in the act of twisting its neck, when urfortunately he squeezed his hydrocele, by his own legs twisting in some way. He immediately experienced acute lancinating pain, and discolouration of the scrotal textures ensued. Three days after the accident my friend Dr. Wylie, of Gourock, tapped and evacuated about half a gill of dark clotted blood. The swelling went on increas. ing till May Ist, when Dr. Wylie asked me to see him. I advised the laying of the sac open, to which the patient consented. I lai, the cavity freely open, evacuated all the blond-clit, and thoroughly washed the cavity with a weak solution of iodine. The testis and cord were distinctly seen. Strips of lint soaked in carbolic oil were then inserted. No constitutional disturbance of any consequence occurred. The wound granulated from the bottom and healed up kindly. In this case the sphymographic tracing was also senile. There is now only the linear cicatrix from the incision, and he says he can freely move the testicle up and down.

Remurks. - These two cases represent the chronic and acute forms of hrematocele of the tunica vaginalis. In the chronic case it is difficult to say how long it had been a hrematocele. But from the pathological appearance it must have been of some years' standing. Probably it occurred on the evening when he became intoxicated, and from the senile condition of the bloodvessels, rupture taking place from a fall or blow; just as in the acute case, jupture took place from the senile condition of the vessels, at least the tendency to rupture was increased by such a condition.

Greenock.

\section{OCCLUSION OF BOTH URETERS; DEATH} BY SYNCOPE.

BY J. VINCENT BELL, M.D., F.R.C.S.,

CONSULTING SURGEON TO ST. BARTHOLOMEW'S HOSPITAL, CHATHAM.

F. $\mathrm{F} \longrightarrow$, aged forty-nine, inclined to be corpulent, but of temperate and regular habits, had occasionally passed small calculi, which he could trace by their symptoms between the kidneys and the urethra. On the evening of Friday, October $26 \mathrm{tb}$, he sent for me, saying that he had passed no 